\title{
The Environmental Factors That Influence Implementation Of Corporate Social Responsibility (CSR) In an Organization
}

\author{
Gloria AnyangoOoko \\ (Department of Communication Studies, Moi University, Kenya)
}

\begin{abstract}
The main aim of business organizations is to make profit. In the global environment, organizations constantly feel the pressure of cut throat competition and thus have to come up with strategies to remain successful. In the last three decades, one of these strategies has been Corporate Social Responsibility (CSR) which simply means organizations giving back to their publics or stakeholders some of the profits they have earned through various projects and activities. This paper presents the findings of a study carried out in Equity Bank, Kenya to determine the factors that influences implementation of its CSR policies and activities. The study took a mixed approach and sample size of 100 was selected using stratified random sampling. Data was generated using questionnaires and interviews. Findings show that though there might be factors like government and intergovernmental standards compelling organizations to engage in CSR, generally organizations do so out of ethical concerns and moral obligation and not necessarily out of pressure.
\end{abstract}

Keywords: Corporate Social Responsibility, publics, stakeholders

\section{Introduction}

Organizations have usually been considered as profit making oriented entities, anything that they do leads to a significant income gain. Indeed most organizations endeavor to make profits and they do everything necessary to achieve this goal. However in the last three decades, the concept of Corporate Social responsibility popularly referred to as CSR has become important if not a must for every organization to embrace. Corporate Social Responsibility (CSR) also known by other names as: corporate responsibility, corporate accountability, stewardship, corporate ethics, community responsibility, corporate sustainability, and so on, is a set of practices that enable organizations to factor in people, planet (environment) and profit into their strategies, decisions and plans. CSR is built on the basis of compliance with legislation and regulation that govern commitments and activities under taken by an organization. An organization's CSR integrates social, environmental and economic concerns of stakeholders and publics into its values, culture decision making, strategy and operations in a transparent and accountable manner which lead to creation of wealth, better health and improved community.

An organization performs its duties and activities in an interrelated environment of its publics among them the governments, employees, financial institutions, investors, shareholders, insurers and others and thus it is only fair that it gives back to the publics that it interacts with, which is simply what CSR does. CSR has many advantages including helping organizations to scan their environments.External environmental scanning consists of the appraisal of opportunities and threats while the internal environment consists of the indicators of strengths and weaknesses. Any change of these factors (internal or external) should be cushioned by the environmental analysis thus CSR is a platform of this (environmental scanning). A company that ensures right allocation of resources and the efficiency of market so as to maximize profit and shareholder return would be a lone ranger in this corporate world where many organizations are contributing to society and building their own prosperity by making their business strategies and performance to be sustainable environmentally, socially, ethically and economically. Miles\&Darroch(2006) recommend that through an active analysis of the environment, for instance, firms account for issues of government regulations, social nature, communities and societies and develop proper response to crises. This is a crucial way that organizations use to address stakeholders and publics.

Despite CSR being not only a noble but profitable venture, most organizations are reluctant to practice CSR as they see it as a money wasting activity. Even those who practice it do not do so fully and willingly. They invest very little money in it just so they can comply with government requirements. However, there are environmental factors that may compel organizations to embark on CSR activities if they are to survive the cut throat competition that is synonymous with the global business environment today. Further, a number of organizations have not yet paid attention to the factors that influence CSR hence most have ended up experiencing risk of business disruption at high rates. This paper therefore seeks to establish what these factors are and how they impact on an organization's, in this case, Equity Bank, implementation of CSR. It contributes knowledge to the field of Public Relations and specifically, CSR. PR officers will be able to understand the 
factors that influence the institution's corporate social responsibility and thus put measures to strengthen its CSR policies and implementation.

\section{The concept of corporate social responsibility}

\section{Literature Review}

Gibson et al. (2000) define Corporate Social Responsibility (CSR) behavioursas discretionary actions undertaken by companies that are intended to advance the social issues. McWilliams \& Siegel (2006) defined CSR as an action that is performed to further some social good beyond the interests of the firm and that is required by the law. Miles and Darroch(2002) noted that CSR activities are categories of economic, ethical, legal and discretionary activities of a business entity as adapted to the values and expectations from society. They also added that, CSR are the basic expectations of a company regarding initiatives that take the form of protection to public health, public safety and the environment. In this concept, they explained that values and ethics influence the extent of corporations perceived social responsibility that is influenced by societal activities, norms or standards.

Orgriezek (2001) and Coldwell (2001) inferred that CSR regards to all aspects of business behaviour so that the impacts of these activities are incorporated in every agenda. Dahlsrud (2008) did an analysis of several definitions and concluded that CSR is the practice through which firms try to improve all its actions concerned with the five organizational dimensions: stakeholders, social, economic, voluntariness and environmental (cited in Galbreath, 2010).

Present study uses the operational definition of Ferrel (1997)in which he defined CSR as actions of firms carried out to meet the economic, legal, ethical and discretionary responsibilities that are imposed on them by their stakeholders. Economic responsibilities refers to producing profits and meeting consumption needs; legal responsibility of firms is to fulfill their economic operations and mission within the legal framework; ethical responsibilities are the firm`s obligation to obey moral rules defining appropriate behaviours in society and discretionary responsibilities are those business actions that are not mandatory but are anticipated by stakeholders ads an evidence of good citizenship

Maignan\& Farrell (2000) focused on the stakeholder management framework rather than society in general because the operational definition shows that firms are responsible to their stakeholders. Stakeholders are those whose interests are linked with the firms' strategies and they can be shareholders, employees, investors, suppliers, customers and governments. Communities and the natural environment are also stakeholders. Citing Clarkson (1995), Galbreath (2010)posit that this operational definition (Maignan\& Farrell, 2000) only considered that firm survival is based on meeting the needs and anticipations of 'primary' stakeholders because they supply critical resources while 'secondary' stakeholders (e.g. media, potential employees) are actors and not engaged in dealings with the firm.

Therefore, with literature definition of CSR, it can be concluded that CSR is the commitment taken by organizations to strengthen their ethical concepts and social involvement in society, to contribute to economic development of stakeholders, sponsor charitable programs, and also the improvement of services provided. However, on the other hand, Schwartz\& Gibb(1999) argue that CSR can promote incompetence by leading the managers to get involved in areas beyond their expertise, that is, trying to repair society`s ill.

\section{Issues affecting the implementation of Corporate Social Responsibility (CSR) in organizations}

A lot of research articles have focused on the impact of corporate social responsibility (CSR) activities to the organization`s economic stability. However, with corporate failures and scandals researchers have redirected the attention to the stakeholders of corporate governance (CG), CSR accountability, trust and ethics in economic conduct (Anger et al., 2003). Galbreath (2010) and Monks\&Minnow (2000) argue that little theoretical and empirical attention has been paid in understanding the motives why or not organization act in socially responsible ways. Most of the research has dealt with the relationships between CSR and financial performance (Agaowal, 2008) and most emphasis, there has been, is on determining the impact of CSR on financial performance rather than to determine the drivers of CSR as well as corporate performance (Galbreath, 2010).

This research focused on determining what shapes CSR. Other scholars have claimed that the inclination towards socially responsible corporate behaviour differs across countries and much more research to recognize why needs to be done (Domini, 2009). Managers and executives of multinational and multidivisional organizations have interests in the antecedents and significance of CSR. These leaders are informed of the fact that business norms and standards, regulatory frameworks and stakeholders demands for CSR can vary considerably across nations, regions and lines of business (McWilliams et al., 2006). CSR consists of the economic, legal, ethical and discretionary responsibilities of the firms towards their stakeholders (Shaw \& Barry, 1999). According to Daft (2001), demands for CSR come from external stakeholders such as communities and societies with general expectation or government with explicit requirements of social legitimacy. 
Previous studies have also categorized CSR in three different levels and two different approaches (Roozenet al., 2001). The three levels are individual, organizational and societal. Individual factors have examined ethical decision making, ethical attitudes and behaviours for example;Fukukawa et al. (2007) researched the relationship between values and attitudes towards social and environmental stewardship among experienced MBA students. Ibrahim (2008) examined the effect of an individual's degree of religiosity on CSR orientation (cited in Wu et al., 2009). At organization level, studies are concerned with issues of corporate governance, organizational behaviour and decision making, leadership and strategy and stakeholder management and so on.The predominant organizational factors examined in the business ethics and CSR literature include code of ethics, ethical climate or culture, business type, organizational size, rewards and sanctions (Aldrich, 1999; Deegan, 2001). At the social level, there are studies responding to issues related to community growth and development, public interest and welfare, human rights, culture and humanity, policy and regulations and social sustainability development etc. (Zoe, 2007; Grefe, 1995).

The two approaches to business ethics and CSR studies are normative or prescriptive approaches and the more analytically oriented descriptive methods (Galbreath, 2010). The normative approach delineates philosophically based moral obligations and normative rules, and is concerned with the good which has moral values. On the other hand, descriptive or empirical approaches are concerned with explaining and predicting behaviours (Anger et al., 2003) and studying how various factors influence ethical decision-making and its process.

Scholars (Carroll \& Hoy, 1984; McWilliams et al., 2006) have also viewed that strategic planning is a crucial way that organizations use to address stakeholders to assess their expectations. Through an active analysis of the environment, for example, organizations account for issues of government regulations, social nature, communities and societies and develop proper responses. Zoe (2007) defined strategic planning as "the articulation and elaboration of strategies, or visions, that already exist". Miles\&Darroch (2006) argued that an organization`s strategic planning efforts should guide all those activities necessary to adapt the environment, also including those associated with corporate social responsibility.

Agaowal (2008) asserts that a business organization only contributes fully to a society, if it is highly profitable and has socially responsible agendas. A study by Windsor (2001) showed that social responsibility is achieved when the corporation or organization conforms to the prevailing norms and expectations of social performance in a given society (Cited in Domini, 2009). The characteristics of the business and management of an organization will influence the likelihood of an organization or firm to engage in CSR since CSR activities are charitable and discretionary. Galbreath (2010) argues that an organization may decide to take a proactive attitude on ethical issues in the absence of specific pressures for that organization to act, which is, voluntary.

The monitoring of an organization by stakeholders may be associated with the size of the firm or organization thus their level of social involvement. Boatwright 1997) found out that heavy manufacturing companies in smelting and chemical production are more closely monitored for they are perceived to be more harmful to the environment and natural habitats. A study by Thompson \& Smith (1999) also reveals that small businesses have not been encouraged to overlook social activism and to concentrate instead on avoiding irresponsible behaviour which is contrary to the perception that size of an organization determines its involvement in CSR (cited in Lu et al., 2009).

CSR is also influenced by ethics of the organization. Daft(2001) contended that people believe businesses are amoral, when in fact they generally embrace the values of ethics in doing business. One of the factors that they cited to legitimize their argument or stand is society, which expects moral behaviour of the business when it cries out against immoral labour practices or environmental policies. Therefore, ethical motivation can guide an organization to do the right thing without any external pressure or governmental constrain.

\section{Methodology}

The researcher used a mixed approach where both qualitative and quantitative techniques were used. Stratified random sampling was used to get a sample size of 100 out of the 200 employees and customers of Equity Bank Group, Head Office Branch in Nairobi. The strata included; management (10), general staff (30) and customers (60). A questionnaire was used to generate quantitative data then data analyzed using descriptive statistics. The qualitative sample was 20 selected purposively out of the 100 respondents. Interviews were used to collect the qualitative data which was then analyzed thematically.

Table 1:Sampling Table

\begin{tabular}{|l|l|l|}
\hline Population category & Population frequency & Percentage \\
\hline Management & 5 & $10 \%$ \\
\hline Staff & 20 & $30 \%$ \\
\hline Customers & 75 & $60 \%$ \\
\hline \multicolumn{1}{|c|}{ Total } & $\mathbf{1 0 0}$ & $\mathbf{1 0 0 \%}$ \\
\hline
\end{tabular}




\section{Findings}

Respondents put forward the following factors as major influencers of CSR policy implementation at Equity Bank:

\section{Government and intergovernmental bodies}

As seen from the chart below, $40 \%$ of the Equity Bank managerial employees of the organization believed that the CSR activities is influenced by governments and intergovernmental bodies while $60 \%$ were of the contrary inferring that the organization through its own policies and strategic plans participate in CSR.

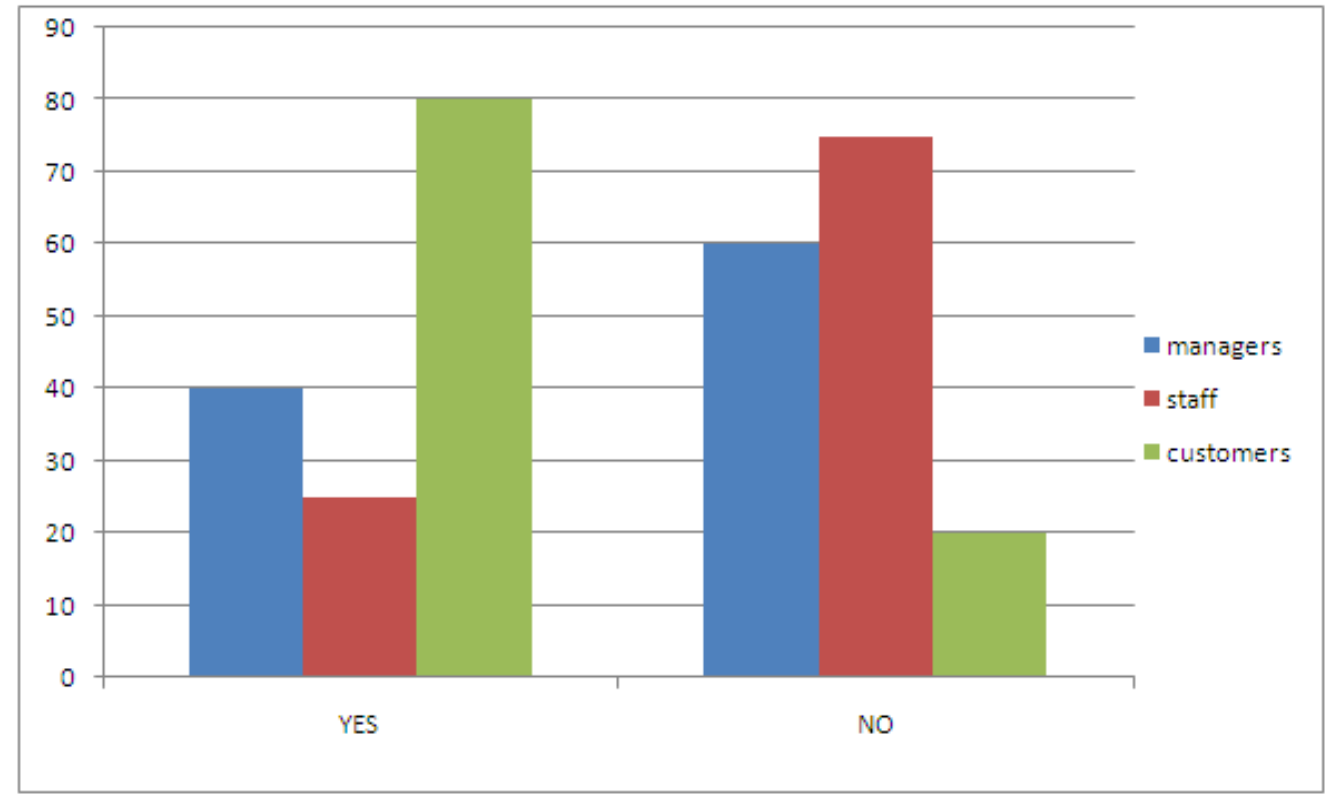

Figure 1: Influence of governments and intergovernmental bodies on CSR

Among the other staff in different departments in the organization, through the use of questionnaires, $25 \%$ confirmed that the government and intergovernmental policies forced the organization to participate in CSR activities. These were 5 out of the 20 respondents interviewed. The other 15 which represented $75 \%$ of the respondents were of contrary opinion explaining that most of the CSR activities are internally driven and strategized. 60 of the customers interviewed which represented $80 \%$ of the respondents said that the CSR activities of an organization are due to the influence of governments and intergovernmental bodies while the remaining 20\% believed that the organization itself planned its CSR activities without the interference of any government or intergovernmental body because they independent organizations.

On further probing, the research findings revealed that Equity Bank Group and other organizations has its corporate social responsibility activities being monitored and under the policies of government and intergovernmental bodies which do support and encourage CSR The Equity Bank has, therefore, created its CSR activities in relation to government's requirements so as to help its publics. Equity Bank offers bursaries for secondary and tertiary students under their projects such as 'Wings to Fly' and 'University Education Fund' respectively. The policies of these two projects follow the guidelines of awarding bursaries as stipulated by the Kenya Bureau of Standards. Other international policies like the International Standards Organization (ISO) were also mentioned to be influencing the organization to undertake CSR activities so as to be ISO compliant.

From this finding, this study concluded that the CSR activities of an organization are influenced partially by the governments and intergovernmental bodies through their policies for this represented $67 \%$ of the respondents. $33 \%$ of the total respondents believed that the CSR activities of an organization are the sole initiatives of the organization for CSR activities are discretionary not due to compliance of policies set.

\section{Globalization}

Theory deduced that the CSR activities of an organization that operates in different countries such as the Equity Bank Group in five countries of Eastern Africa are influenced by globalization. The organization has 
to follow the global social norms, environmental and ethical issues in the areas that it operates in in order to succeed.

Table 2: Influence of globalization on CSR

\begin{tabular}{|l|l|l|}
\hline \multicolumn{1}{|c|}{ Population } & Yes in \% & No in \% \\
\hline Management & 80 & 20 \\
\hline Staff & 75 & 25 \\
\hline Customers & 40 & 60 \\
\hline
\end{tabular}

Source: Author, 2014

As in theory, the fieldwork results also showed that in the Equity Bank Group $80 \%$ of the management staff believed CSR activities are influenced by the geographical area they operate in thereby confirming that globalization influences the CSR activities of an organization. $20 \%$ of respondents inferred that an organization can do the same CSR activities in different countries because most are philanthropic adding that social needs are almost same everywhere in Eastern Africa.

The other staff -non-management- $75 \%$ of the respondents confirmed that globalization influences the CSR activities of an organization. Most of the interviewed explained that an organization has to operate in different countries but its activities should be for sustainably developing the areas they operate in. They majored on issues of labour, remuneration, climate change, ethics and gender equity which are globalized issues which according to them influence the CSR activities of an organization.

$40 \%$ of the customers believed globalization influenced CSR activities of an organization explaining that an organization should be conventional with its activities in host countries. $60 \%$ of the respondents were of contrary opinion to this explaining that the CSR activities are determined by the headquarters of an organization for profitability purposes and most CSR activities are in the mother country other than the other host countries.

From the findings, $49 \%$ of the total respondents said that globalization influences the CSR activities of an organization while $51 \%$ were of contrary opinion. This may be because of the level of education of most of the respondents (customers) who are not beyond the O-Level and most are not aware of issues of globalization.

\section{Customers and Investors}

Dr. Mathew J.(2005) argued that now there is incontrovertible evidence that superior environments and social performance does in fact have direct impacts on the risk levels, profitability and share price performance of publicly traded companies are obliged to report on their plans for incorporating environmental and social risk assessments into their investment strategies, so did the findings of this study show the importance and fundamental necessity of CSR activities by an organization so as to encourage investors and customers.

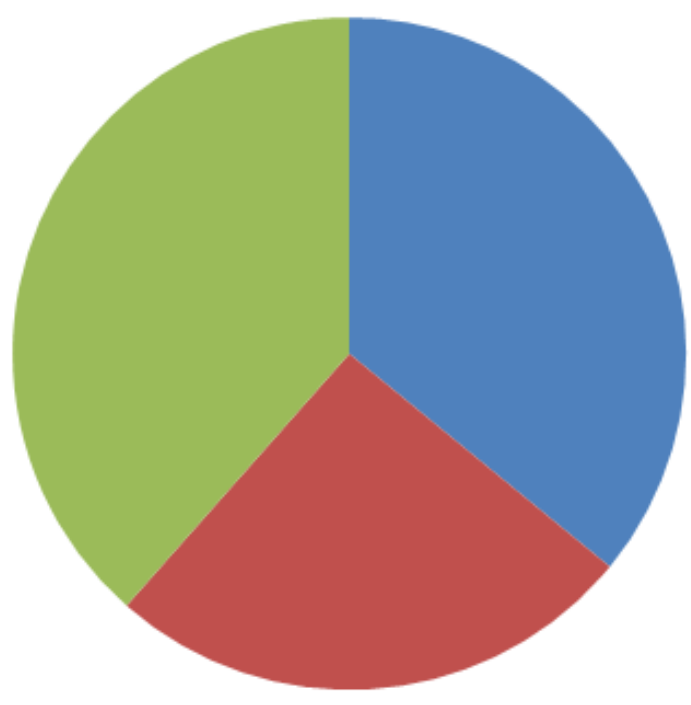

customers- $84 \%$

management-60\%

- Staff- $90 \%$

Figure 2: Influence of customers and investors on the CSR activities of an organization.

The research findings found that customers and investors influence the CSR activities of an organization. $60 \%$ of the managerial staff respondents believed that the investors set the thresholds to what activities an organization involves itself in. They add that investors should see that their investment leads to 
sustainable development. $40 \%$ differed with this explaining that customers and investors are part of an organization and the organizations engage in CSR activities to influence customers and investors to their advantage and profitability.

18 out of the 20 staff respondents which represent $90 \%$ agree that the customers and investors determine the CSR activities of an organization explaining that they are the backbone of an organization. 2 respondents representing $10 \%$ however differed with this. $84 \%$ of customers believe that CSR activities are influenced by customers and investors explaining that different regions require different activities thus organizations are forced by their customers and investors to participate in the activities they believe are beneficial to them.12 of the customer respondents representing $16 \%$ explained that organizations involve themselves in CSR activities so as to advertise their products and services to the publics. $89 \%$ of all the respondents believe that customers and investors influence the CSR activities of an organization.

\section{Social and Environmental groups}

Companies or organizations are increasingly finding themselves liable to attack from activists. These attacks can take wide variety of forms but the implications for companies or organizations are enormous (J. Hancock, 2005). This research confirmed that social and environmental groups influence the CSR activities of an organization. $97 \%$ of the respondents believed that social and environmental groups acting as activists influence the CSR activities of an organization through their activism.

Table 3: Influence of social and environmental groups on Corporate Social Responsibility activities of an organization.

\begin{tabular}{|l|c|c|c|}
\hline Population & No of respondents & $\begin{array}{l}\text { \% of respondents } \\
\text { Who said YES }\end{array}$ & $\begin{array}{l}\text { \% of respondents } \\
\text { who said NO }\end{array}$ \\
\hline Management & 5 & 100 & 0 \\
\hline Staff & 20 & 100 & 0 \\
\hline Customers & 75 & 96 & 4 \\
\hline
\end{tabular}

Source: Author (2014)

$100 \%$ of the managerial and other staff believed that if an organization is in the spotlight by activist groups such as social and environmental groups they use CSR activities to divert public attention. An organization can lose its stakeholders and be rendered to losses due to activism and therefore the organization has to quickly address issues raised by activist groups so as to avoid litigation or even closure of business.

$96 \%$ of the customers who responded believed that social and environmental groups force an organization to participate in CSR activities. They explained that if an organization is pressured by these activist groups, they give in because mostly the activists have support of other stakeholders. $4 \%$ were of a contrary opinion. This research finds out that social and environmental groups are a threat to an organization which is not socially responsible in its operations.

\section{Advances in Communication Technology.}

Communication creates a link between an organization and its stakeholders through acquisition of information and relay of feedback. Communication technology has enabled this to happen but the advances in communication technology have changed the extent of content that reaches the stakeholders or publics thus its activities being easily monitored. $94 \%$ of the respondents in the research confirmed this and explained that organizations have social media accounts, blogs and use the internet frequently to serve their publics. 


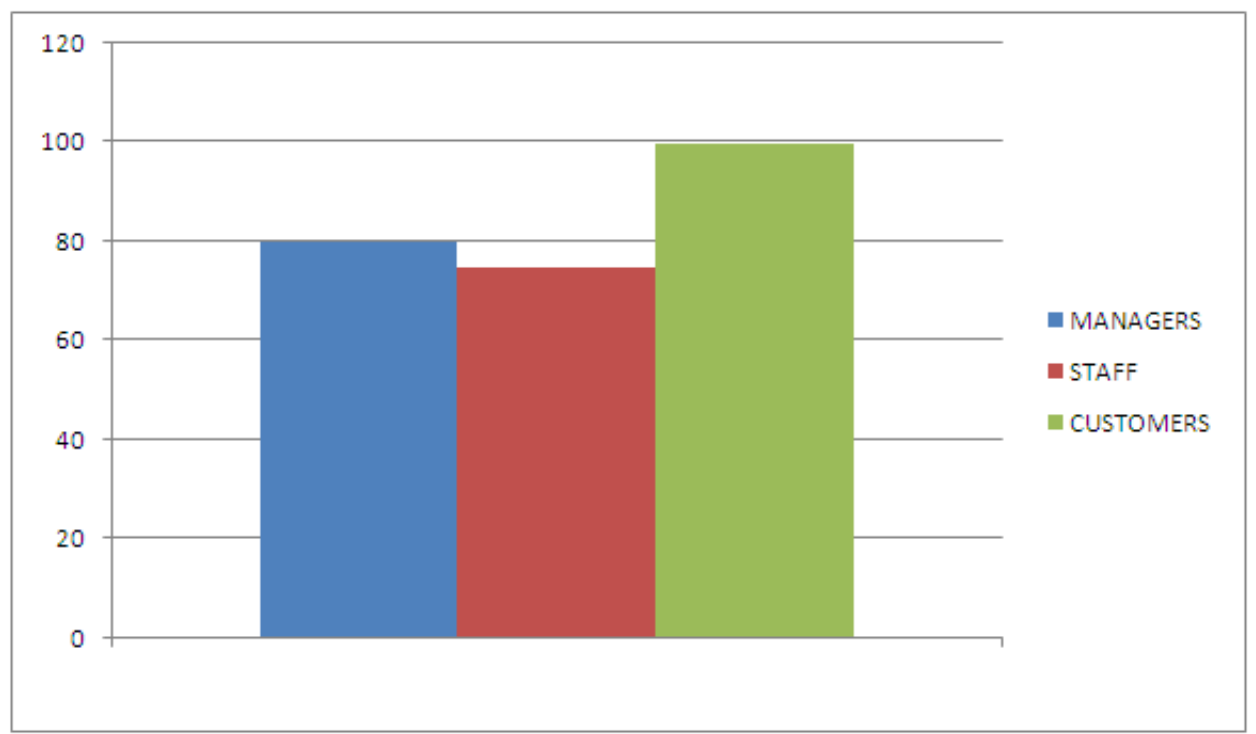

Figure 3: Influence of advances in communication technology on CSR of an organization.

$80 \%$ of the managerial staff believes that the advances in communication technology have made the organization to be socially responsible because their publics are readily informed of their activities through the different communication channels. Organizations have to participate in CSR activities so as to build a positive image with its publics. $20 \%$ of the respondents were of contrary opinion sighting that the advances in communication technology only enable the organization to perform its operations easily rather than enabling scrutiny from its publics and causing adverse consequences to the organization.

$75 \%$ of the other staff respondents believed that the advances in communication technology have brought awareness of the activities of an organization to its publics thus forcing it to always participate in CSR activities. $25 \%$ of the respondents said that although the advances in technology have given awareness to its publics, these advances do not have a direct impact on the operations and activities of an organization.

$100 \%$ of the customers who responded believed that due to the advances in communication technology, they are now able to comment on the activities of an organization and sometimes influence the organization`s activities by informing other publics of unsocial responsible behaviour of an organization. They further explained that organizations are now keen on what publics give as opinions in communication platforms such as the social media. The study findings show that most publics receive information from not only the organization`s communications such as brochures, emails, letters, yearly reports or notices but also through other channels of communication which some are independent.

\section{Corporate Ethics}

The values, norms and beliefs of an organization identifies it within the environment it operates in. corporate ethics influences the corporate social responsibility of an organization as per the findings of this study. Only the staff was interviewed on this aspect because most of the customers are not conversant with the ethics of the organization. $88 \%$ of the respondents believed that corporate ethics influences CSR activities of an organization.

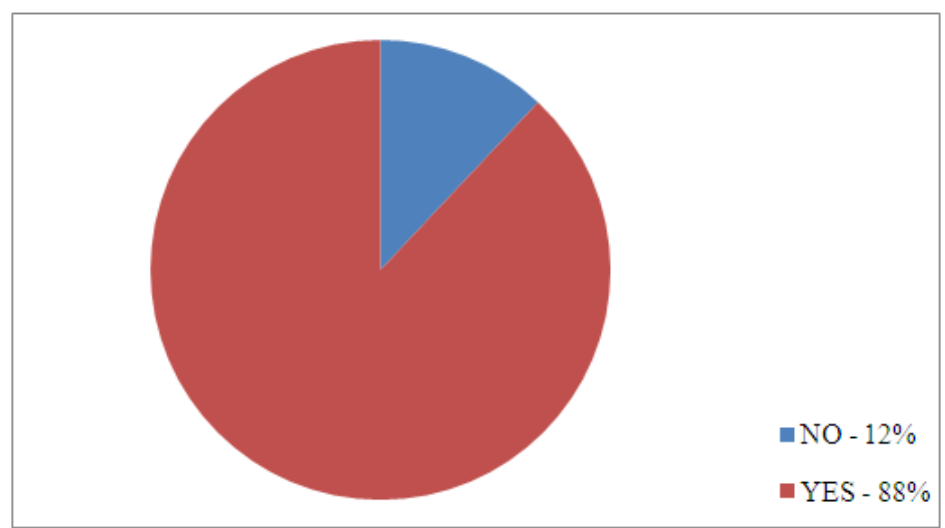

Figure 4: Influence of corporate ethics on CSR of an organization. 
$95 \%$ of the staff from the other departments believed that corporate ethics influences the CSR activities of an organization. They explained that because an organization should follow its norms, values and believes to the letter, it cannot go back on socially responsible activities such as on capacity building, environmental protection, anticorruption, etc. 1 respondent representing 5\% was of contrary opinion arguing that corporate ethics are just the pillars of an organization to its business environment.

$60 \%$ of the managerial staff believed that corporate ethics influences an organization`s CSR activities. They argued that for an organization to participate in CSR activities, the guiding principles are the ethics upheld by the organization which therefore influences it to participate in activities that leads to sustainable development. $40 \%$ of the respondents argued that corporate ethics are the fundamentals of the organization in its business operations but not the determiners of activities that an organization participates in.

\section{Discussion}

There are several factors that influence organizations' implementation of CSR including; governments and intergovernmental bodies, globalization, customers and investors, social and environmental groups, advance in communication technology and corporate ethics.In this study, corporate ethics is the major factor that motivates organizations to engage in CSR activities. This implies thatorganizations are influenced by their own business ethics and moral obligation to give back to its publics. Government may impose rules, globalization and consequently competition may compel organizations to engage in CSR activities; however at the end of the day, organizations themselves analyze and recognize the essential need of CSR activities and make an independent decision to actively engage in them or not.

\section{Conclusion}

The organization`s survival depends on the customers use of their products and service and also the investors hand in expansion of operations. Therefore, organizations should participate in CSR activities and not only for the organization`s profitability; every activity undertaken by an organization should bring profit to the society through activities of education, health, environmental, social, ethics, etc. and the social and environmental strategic plans of investors. It is recommended that the prime responsibility of an organization is to make sure its activities leads to sustainable development within all host countries for the community and society at large. Through CSR activities, the areas of operation are protected from social, ethical and environmental degradation. The Equity Bank Group and other organizations should put enough investment on CSR activities so as to achieve profitability for its shareholders and stakeholders.

\section{References}

[1]. K. Domini, Ethical investing (Reading, MA: Addison-Wesley, 2009).

[2]. McWilliams; D.S. Siegel \& P.M. Wright, Corporate social responsibility: strategic implications. Journal of Management Studies, 43(1), 2006, 1-18.

[3]. D. Deegan, Managing activism (London: IPR, 2001)

[4]. D.F. Aldrich, Mastering the digital market place (NY: John Wiley \& Sons, 1999).

[5]. E. Grefe, The new corporate activism: harnessing the power of grass roots tactics for your organization (NY: McGraw Hill, 1995).

[6]. J. Boatwright, Ethics in Finances (Oxford: Blackwell Publishers, 1999).

[7]. J. Galbreath, Drivers of corporate social responsibility: the role of formal strategic planning and firm culture (London: British academy of Management, 2010).

[8]. L. Wu; G. Pringato\& A. Mark, Customer perceptions of corporate social responsibility of service forms (University Park, PA: Sage Publication, 2009).

[9]. M.P. Miles \& J. Darroch, The role of strategic conversations with stakeholders in the formation of corporate social responsibility strategy, Journal of Business Ethics, 69(2), 2006, 195-205.

[10]. O. C Ferrell \& J. Fraedrich, Business ethics (Boston: Houghton Mifflin, 1997).

[11]. P. Schwartz \& B. Gibb, When good companies do bad things: responsibility and risk in an age of globalization (NY: John Willey \& Sons, 1999).

[12]. P.Anger; P. Burke; T.M. Devinney\&J.J. Louvieve, What will consumers pay for social product features, Journal of Business Ethics, 42(3), 2003, 281-304.

[13]. R. Daft, Organization theory and design (Cincinnati, Ohio: South Western, 2001).

[14]. R. Monks \& N. Minnow (eds.), corporate governance (Blackwich: Oxford, 2000).

[15]. S.D. Zoe, Business Ethics and corporate social responsibility in the e-economy: a commentary (2007).

[16]. S.K. Agaowal, Corporate social responsibility in India (ND: Sage Publications, 2008).

[17]. V. Gibson, S. McKenzie, \& J. Baker, Overview of social investment and fiduciary responsibility. Journal of Business Ethics, 20(1), 2000, 7-25.

[18]. W.H. Shaw \&V.B. Barry, Moral issues in business (Belmond, CA: Wadsworth Publishing Company, 1999). 